\title{
The Extended Posterior Circumferential Decompression Technique in the Management of Tubercular Spondylitis with and without Paraplegia
}

\author{
Safak Ekinci ${ }^{1}$, Faruk Akyildiz ${ }^{2}$, Kenan Koca ${ }^{3}$, Omer Ersen $^{4}$, Serkan Akpancar ${ }^{3}$ \\ ${ }^{1}$ Department of Orthopaedic Surgery, Agri Military Hospital, Agri, Turkey \\ ${ }^{2}$ Department of Orthopaedic Surgery, Malatya Military Hospital, Malatya, Turkey \\ ${ }^{3}$ Department of Orthopaedic Surgery, Gulhane Military Hospital, Ankara, Turkey \\ ${ }^{4}$ Department of Orthopaedic Surgery, Erzurum Military Hospital, Erzurum, Turkey
}

Dear Editor,

We have read the published article by Rathinavelu at al. [1] entitled "The Extended Posterior Circumferential Decompression Technique in the Management of Tubercular Spondylitis with and without Paraplegia" with great interest. The study we well written and the authors described a new posterior procedure termed the "Extended Posterior Circumferential Decompression (EPCD)", a technique that manages tubercular spondylitis, in the presence or nonpresence of paraplegia. The objective of the study is noteworthy and we have some questions for authors:

(1) In the study it was written, "During this period, all cases of dorsal, dorso-lumbar and lumbar tuberculous spondylitis cases operated for any indication were performed using this technique." and "Major indication for the procedure was paraplegia in 24 patients (59\%), and contiguous vertebral body destruction with deformity in 17 patients (41\%)." What are the authors' operation indications? In 2008, Oguz et al. [2] developed a classification system for spinal tuberculosis based on seven clinical and radiological criteria. In this system, the researchers divided spinal tuberculosis into three categories by using these criteria, andrecommended specific therapeutic techniques for each type. Are the authors using a classification system to provide guidance in selecting the proper treatment approach for patients with spinal tuberculosis?

(2) Which method did the authors use for differencial diagnosis from malignancy or methastasis before operations? Is the needle biopsy diagnostic significant?

(3) What is the best option for multilevel tuberculosis spondylitis for patients having both thoracal and lumbar complications, with severe kyphosis or collapse?

(4) Some authors advised using intraoperative cell salvage system in vertebral operations [3]. What is the author's opinion about this issue?

We appreciate the author's comments on this concern.

\section{Conflict of Interest}

No potential conflict of interest relevant to this article was reported. 


\section{References}

1. Rathinavelu B, Arockiaraj J, Krishnan V, Amritanand $\mathrm{R}$, Sundararaj GD. The extended posterior circumferential decompression technique in the management of tubercular spondylitis with and without paraplegia. Asian Spine J 2014;8:711-9.

2. Oguz E, Sehirlioglu A, Altinmakas M, et al. A new classification and guide for surgical treatment of spinal tuberculosis. Int Orthop 2008;32:127-33.

3. Ersen O, Ekinci S, Bilgic S, Kose O, Oguz E, Sehirlioglu A. Posterior spinal fusion in adolescent idiopathic scoliosis with or without intraoperative cell salvage system: a retrospective comparison. Musculoskelet Surg 2012;96:107-10. 